\title{
Stress Test For The Financial Optimization Models During The 2009 Recession
}

Hamid Ahmadi, California State University, USA

James A. Kuhle, California State University, USA

Sanjay Varshney, California State University, USA

\begin{abstract}
The Sub-prime Mortgage credit crisis has led to a major downturn in virtually all financial sectors and consequently the real estate sector received the brunt of the 2008 - 2009 financial crisis. However, this downturn undoubtedly has provided an opportunity to test what investment strategy could have deflected the shocking force of this crisis and specifically what method could have minimized the risk of the most negatively affected investment -- Equity Real Estate Trust funds. Using ex-post data of EREITs, this research examines the implications and benefits of employing optimal portfolio allocation methods to different size EREIT portfolios during current financial crisis. This study compares the returns of optimally weighted EREIT portfolios to equally weighted EREIT portfolios, against the Dow Jones Equity REIT Index (DJEREIT Index). The results indicate that a properly rebalanced risk-adjusted model portfolio (RAMP) outperforms both an equally weighted portfolio of identical assets and the DJEREIT Index. In fact, the twelveasset optimized portfolio yields a superior return of $12.7 \%$ when compared to a return of an equally weighted portfolio of identical EREITs, and the DJEREIT Index during the three-year time period examined.
\end{abstract}

Keywords: RAMP Model, Financial Models, Optimization Models, REIT

\section{INTRODUCTION}

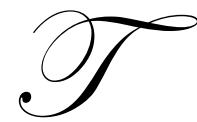

he sub-prime crisis of 2008 has led to significant reductions in returns of all major assets within the U.S. financial system. The real estate market has been especially hard hit. Once housing prices started to drop moderately in 2006-2007 in many parts of the U.S., refinancing became more difficult. Defaults and foreclosures increased dramatically as Adjustable Rate Mortgage (ARM) interest rates reset higher. During 2007, nearly 1.3 million U.S. housing properties were subject to foreclosure, up $79 \%$ from 2006 . The Economist estimated subprime defaults would reach a level between $\$ 200-300$ billion. Falling U.S. housing prices and rising delinquencies in mortgage-market losses, including securities tied to commercial real estate and loans to consumers and companies, may reach $\$ 945$ billion according to the IMF. The financial-services industry has posted losses of $\$ 476$ billion since July of 2007, while average U.S. home prices have fallen $15 \%$. Of course the question remains to what extent this crisis has created a downturn with equity REITs, and according to our preliminary findings, the impact has been unmistakably substantial. Based on initial analysis, the average portfolio returns for this research indicate an unprecedented decrease in returns for the Dow Jones Equity REIT (DJEREIT) Index during the time period from the end of August 2005 to August 2008.

The purpose of this research is to determine whether Risk Adjusted Model Portfolio (RAMP), a cutting edge portfolio optimization model provides better results when compared to the Dow Jones Equity Real Estate Investment Trust Index before and after the sub-prime mortgage crisis. This model will prescribe not only the optimal number of EREITs to hold in a portfolio, but it also computes the optimal weights of each EREIT in an efficient portfolio. 


\section{LITERATURE REVIEW}

The performance of REITs has been a topic for debate over the last twenty plus years within the body of real estate literature. Depending on time periods analyzed and types of REITs invested in, the answer to performance varies. However, the implications for investment opportunity abound if it can be demonstrated that REITs either are or are not efficiently priced assets. If REITs are less than efficiently priced then a strategy application of efficiently selecting these assets using modern portfolio analysis would tend to be financially rewarding. In this section, we examine selected articles that relate first to the efficiency of REIT prices and then secondly to the application and impact of efficient portfolio selection processes to obtain superior returns.

Chen, $\mathrm{Ho}, \mathrm{Lu}$, and $\mathrm{Wu}(2005)$ examination of whether the addition of real estate assets can significantly expand the mean-variance efficient frontier beyond stocks that are already publicly traded, to provide substantial diversification benefits for investors or fund managers, is an intriguing question. Results of this study indicate that REITs before 1985 are unable to provide additional diversification benefits. However, more recent REITs over the period from 1986-2002 do improve the mean-variance frontier and expand the investment opportunity set.

Salter (2006) tested the relative risk-adjusted performance of NASDAQ REITs using both a naïve and optimal portfolio allocation strategy. The results of this study indicate that a scientific statistical approach to portfolio selection, dominates naïve methods (i.e. equally weighted) methods for the time period considered from 1995 to 2005. In addition to Markowitz optimization, the author also uses stochastic dominance, which is shown to produce the greatest growth in capital on a non-risk adjusted basis.

Anderson and Springer (2003) develop a portfolio asset selection model based on REIT operating efficiency and pricing multiples. Portfolios are constructed that exhibit relatively high operating efficiency, trading at low prices. The results of this research indicate that these pre-screened portfolios have superior performance during the first year of selection. Further superior performance also ensued in years two and three, suggesting there are potential rewards for investing in REITs through a pre-screening process and then using efficient portfolio selection techniques in indentifying superior performing portfolios. Using monthly REIT data from the National Association of Real Estate Investment Trusts, Inc. (NAREIT), Jirasakuldech and Knight (2005) test the efficiency of Real Estate Investment Trusts (REITs) markets from 1972 to 2004. The data is segmented chronologically to take into account the effect of the Tax Reform Act of 1986 and the effect of the explosive growth in market capitalization that began in the early 1990s. In addition, a non-parametric runs test shows evidence of weak-form inefficiency in the stock market and all types of REIT markets except EREITs.

Kuhle and Alvayay (2000) conducted a runs test on both daily and monthly EREIT data to determine if EREIT prices moved randomly (supporting efficient pricing) or if discernable statistical patterns existed. The results of both the runs test and the autocorrelation test would suggest a degree of inefficiency in the EREIT market, at least for the time period examined (from January 1989 through October 1998). The runs test provided evidence of general price dependency, and the autocorrelation test supports this conclusion.

Stevenson (2002) examines the out-of-sample performance of Equity portfolios based on market sectors, with the aim of examining the potential improvements in performance resulting from alternative methods designed to reduce estimation error. The results indicate the best performing portfolio is not the "Minimum Variance Portfolio" (MVP) but alternative tangency portfolios Ahmadi (2009) and Ahmadi and Khoroujik (2007). This occurs despite the instability in the estimated allocations, the presence of corner solutions and the frequent large shifts in the weights. Ahmadi, H. and Galindo, C. (2005) and Ahmadi, H. \& Soriano B. (2003) validate this hypothesis.

In addition to the articles cited above, a number of other studies have been conducted and are relevant to this current research. These include articles on issues of REIT efficiency, asset allocation, and Markowitz optimization. The following list includes conducted research on many of these topics: Addae-Dapaah, Wee, and Ebrahim (2002), Booth (2002), Stevenson (2002), Tse (2002), Lewis, Springer, and Anderson (2003), Chui, Titman, and Wei (2003), Chen, Ho, Wu, and Lu (2005), among others. Since it is not possible to discuss these works in detail in this study, the above list is offered as partial treatment of the relevant topics that impact this current research. 


\section{DATA AND RESEARCH DESIGN}

The sample for this research consists of 5 years of ex-post daily prices and dividends from August 8, 2003 to August 25, 2008 of 18 EREITs from various stock exchanges from a pool of over 100 EREITs that were listed in the National Association of Real Estate Investment Trusts, Inc (NAREIT). While there were many EREITs from the total population that had daily return data going back five years, many of those EREITs had very "thin" trading histories. This resulted in a significant variation in returns due to the small number of shares traded for any given observation. The 18 EREITs selected were based on their relative trading strength and their price availability over the past five years. It was found that these EREITs had over 100,000 shares traded on the various trading days.

Daily observation data over the past five years allowed us to categorize the results into three time periods. These time periods are reflective of the overall performance levels of EREITs during the total time period. The first time period from August, 2005 to August, 2006 exhibits positive gains in EREITs. This rather robust performance is mirrored by the annualized return of $18.9 \%$ for the DJEREIT Index. The next time period from August 2006 to August 2007 was a relatively flat period for EREITs. This performance was reflected in a close to zero (-.075) per year for overall return as measured by the DJEREIT Index. The third period from August 2007 to August 2008 was a year of major downturn for the EREIT market. This is evidenced by the negative $18.1 \%$ overall return on the DJEREIT Index during this time period. Therefore, the data provided three distinct periods to test and compared an optimal portfolio model to an equally weighted strategy versus the return on the overall Dow Jones Equity REIT Index.

\section{THE MODEL}

There are three common approaches to portfolio optimization - the Equal Weights (EW) approach, the Minimum Variance Portfolio (MVP) approach, and the Modern Portfolio Theory (MPT) approach. While each of these methods can help a portfolio manager respond to his clients' needs, there is an additional approach that can be used to generate an optimal portfolio - the Risk-Adjusted Managed Portfolio (RAMP) model. While the MVP and MPT approaches rely on variance to determine risk and help portfolio managers determine whether to buy or sell a particular asset, RAMP considers beta and variance. Specifically, RAMP is a two-stage model that provides us with a simple, but effective means of selecting stocks and determining the appropriate proportions of each to hold in our portfolio. The first stage of the RAMP model uses the Treynor Index to help us select stocks for our portfolio, while the second stage uses the Sharpe Index to determine what proportion of our portfolio should be invested in each stock.

\section{Stage 1 -Stock Selection}

Since we need to determine which stocks to include in our optimal portfolio, the first stage of the RAMP model assists us with stock selection. Of course, it would be very easy to form such a portfolio if there were a single number we could use to decide whether or not to include a particular stock in the portfolio. The RAMP optimization model finds this key number and tells us to include in our portfolio any stock with a Treynor Index that exceeds it.

$$
\text { Treynor }=\frac{\left(R_{j}-R_{f}\right)}{\beta_{j}}
$$

Where $R_{j}$ is the rate of return for stock " $j$," $R_{f}$ is the risk-free rate of return and $B_{J}$ is the beta value for stock " $j$ ". Note that both the market rate of return $R_{m}$ and the risk-free rate of return $R_{f}$ result from general stock market fluctuations and are not due to the work of a portfolio manager. In other words, $\left(R_{m}-R_{f}\right)$ is the return of an "unmanaged portfolio". If the Treynor Index, which is the risk-adjusted return of stock $j$, is greater than $\left(R_{m}-R_{f}\right)$, then stock $\mathrm{j}$ outperformed the unmanaged market portfolio and stock $\mathrm{j}$ is a candidate to be included in our optimal portfolio. Once again, the general rule for including or excluding stocks from our optimal portfolio is to include the stock if its Treynor Index is greater than the key number calculated by RAMP. We will call this key number the cutoff number. 


\section{Stage 2 - Determining Optimal Proportions}

Inclusion and exclusion of stocks is the first part of the RAMP model. The second task is to find the proportions to be invested in each included stock in order to create an optimal portfolio. This optimization process is similar to MPT in that the proportions of the market portfolio, or Portfolio M, are determined by maximizing the slope of the Capital Market Line (CML). In other words, we hold stocks in the proportions dictated by the maximum Sharpe Index.

In summary, the RAMP model compares a stock's risk-adjusted return (as measured by the Treynor Index) with the cut-off number mentioned above to determine whether to include the stock in our portfolio. It then uses the Sharpe Index to find the proportion of funds to be invested in each stock in order to create an optimal portfolio. Thus, the optimal portfolio we select using the RAMP model will not only have passed the Treynor Index test, but will also have secured the highest possible return at any given level of risk.

\section{Rebalancing}

An investor must also pay close attention to rebalancing, which is the periodic adjustment of the proportion of the portfolio invested in each asset. Rebalancing is a means of maintaining the optimal asset mix within the portfolio through purchase and sale of individual assets. After an investor decides how to allocate his or her assets, the decision as to what portfolio rebalancing strategy to use is probably the most important factor in creating and maintaining a successful portfolio. As the economic environment and market conditions change, investors must rebalance their portfolios to incorporate current and relevant information into their asset allocation processes.

So how often a portfolio should be rebalanced? The answer to this question is partially subjective and partially determined by factors such as the type of investment strategy and the amount of work required of portfolio managers in the rebalancing process. In general, we can distinguish between the following two approaches to portfolio rebalancing:

Calendar Rebalancing: Rebalancing the portfolio to its optimal allocation at a certain frequency such as weekly, biweekly, monthly, quarterly, etc.

Threshold Rebalancing: Rebalancing the portfolio to its optimal allocation once it exceeds a certain range. For example, the portfolio could be rebalanced when the portfolio weights differ by more than ten percent from the optimal weights.

\section{RESULTS}

The research design initially uses the first 29 months of daily observations from April 8, 2003 to December 31, 2005 to compute required statistics for each of the EREITs in the sample and determine correlated market values that is needed by the RAMP model. Then, from August 1, 2005 to August 25, 2008 several portfolios were formed - one set of portfolios comprised of 3 to 18 EREITs with optimal weights generated by the RAMP model based on the statistics from the first 29 months and another set comprised of 3 to 18 EREITs with equal weights.

The performance of the 12-asset portfolios is presented in Graph-1 below. Graph-1 displays the performance of portfolios formed by RAMP, Equal Weight, and REIT Index. REIT Index is labeled as "Market" in the Graph-1. The results clearly demonstrate that the portfolio formed by RAMP model significantly outperformed other portfolios during the 2008 down market. 
Graph 1

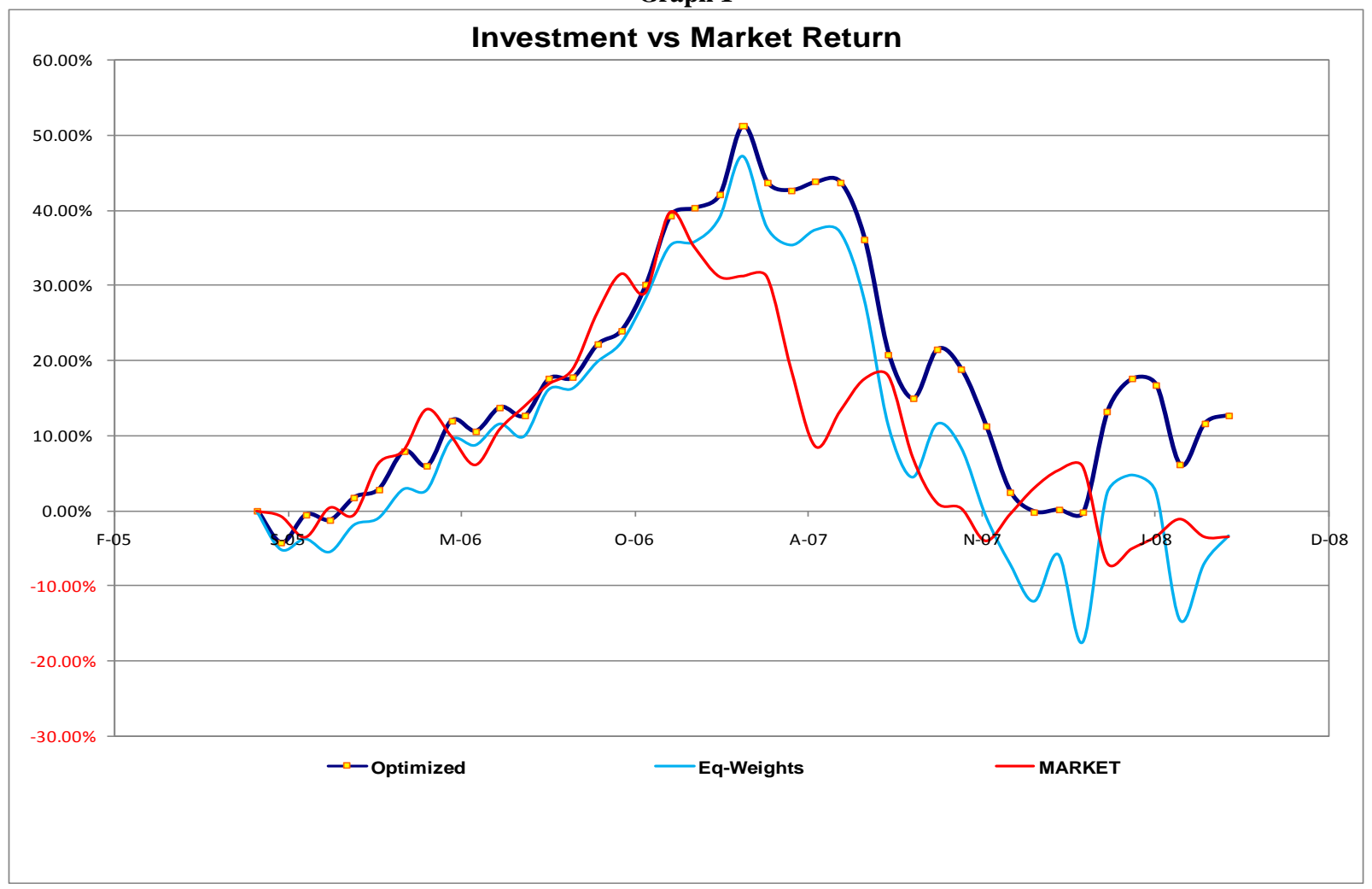

Table 1 shows the categorized returns for the 12-REIT portfolio from August 2005 to August 2008 for the optimized, equal-weights, and the REIT Index. As illustrated in Table 1, the cumulative return for the optimal REIT portfolio was $15.82 \%[(1+0.2014)(1+0.0363)(1-0.0698)-1]$ over the three year period starting 8/01/2005 through $8 / 25 / 2008$. Similarly, over the same time period the cumulative return for the equal weight portfolio was $-2.21 \%$ and for the Index was $-3.42 \%$.

Table 1

\begin{tabular}{|c|c|c|c|}
\hline & \multicolumn{3}{|c|}{ Annualized Returns } \\
\hline 12-REIT & Optimized & Equal Rates & REIT Index \\
\cline { 3 - 4 } Aug. 2005 to Aug. 2006 & 0.2014986 & 0.1578128 & $\mathbf{0 . 1 8 8 7 1 4 8}$ \\
\hline Aug. 2006 to Aug. 2007 & 0.0363451 & 0.0597050 & 0.0074984 \\
\hline Aug. 2007 to Aug. 2008 & 0.0698704 & 0.1017895 & 0.1814218 \\
\hline 3-Year Returns & $\mathbf{1 5 . 8 2 \%}$ & $\mathbf{- 2 . 2 1 \%}$ & $\mathbf{- 3 . 4 2 \%}$ \\
\hline
\end{tabular}

It is important to note that the returns of all portfolios are standardized and adjusted for risk to make comparisons possible. That is, the Graph-1 illustrates the risk-adjusted returns for all portfolios so that the standardized performance of the RAMP optimization model can be compared with the risk-adjusted performance of other portfolios and the REIT index.

Table 2 provides the cumulative return data for optimal and equally weighted portfolios as well as the DJEREIT Index ranging in size from 10 to 18 assets. Notice also that the summary statistics are broken down into three different time categories. These include August 2005 to August 2006, August 2006 to August 2007, and August 2007 to August 2008. In addition, the results for the entire three-year period, August 2005 to August 2008 are reported as well. 
Table 2

\begin{tabular}{|c|c|c|c|}
\hline & \multicolumn{3}{|c|}{ Annualized Returns } \\
\hline 10-REIT Portfolio & Optimized & Equal Weight & REIT Index \\
\cline { 2 - 4 } Aug. 2005 to Aug. 2006 & 0.2455513 & 0.1777021 & 0.1887148 \\
\hline Aug. 2006 to Aug. 2007 & 0.0066441 & -0.0751831 & -0.0074984 \\
\hline Aug. 2007 to Aug. 2008 & -0.1388676 & -0.1553518 & -0.1814218 \\
\hline 3-Year Returns & $\mathbf{7 . 9 7 \%}$ & $\mathbf{- 8 . 0 0 \%}$ & $\mathbf{- 3 . 4 2 \%}$ \\
\hline \hline 11-REIT Portfolio & Optimized & Equal Weight & REIT Index \\
\hline Aug. 2005 to Aug. 2006 & 0.2038767 & 0.1596070 & 0.1887148 \\
\hline Aug. 2006 to Aug. 2007 & 0.0373150 & -0.0574233 & -0.0074984 \\
\hline Aug. 2007 to Aug. 2008 & -0.0783560 & -0.1199721 & -0.1814218 \\
\hline 3-Year Returns & $\mathbf{1 5 . 0 9 \%}$ & $\mathbf{- 3 . 8 1 \%}$ & $-\mathbf{3 . 4 2 \%}$ \\
\hline \hline 14-REIT Portfolio & $\mathbf{0 p t i m i z e d ~}$ & Equal Weight & REIT Index \\
\hline Aug. 2005 to Aug. 2006 & 0.1674039 & 0.1571270 & 0.1887148 \\
\hline Aug. 2006 to Aug. 2007 & 0.0270838 & -0.0602500 & -0.0074984 \\
\hline Aug. 2007 to Aug. 2008 & -0.0508346 & -0.1246038 & -0.1814218 \\
\hline 3-Year Returns & $\mathbf{1 3 . 8 1 \%}$ & $\mathbf{- 4 . 8 1 \%}$ & $\mathbf{- 3 . 4 2 \%}$ \\
\hline \hline 17-REIT Portfolio & Optimized & Equal Weight & REIT Index \\
\hline Aug. 2005 to Aug. 2006 & 0.2137011 & 0.1566188 & 0.1887148 \\
\hline Aug. 2006 to Aug. 2007 & 0.0239436 & -0.0585856 & -0.0074984 \\
\hline Aug. 2007 to Aug. 2008 & -0.1336592 & -0.1356302 & -0.1814218 \\
\hline 3-Year Returns & $\mathbf{7 . 6 7 \%}$ & $\mathbf{- 5 . 8 8 \%}$ & $\mathbf{- 3 . 4 2 \%}$ \\
\hline \hline 18-REIT Portfolio & $\mathbf{0 p t i m i z e d ~}$ & Equal Weight & REIT Index \\
\hline Aug. 2005 to Aug. 2006 & 0.1999248 & 0.1468220 & 0.1887148 \\
\hline Aug. 2007 to Aug. 2008 & -0.1090814 & -0.1217766 & -0.1814218 \\
\hline 3-Year Returns & $\mathbf{9 . 9 7 \%}$ & $\mathbf{- 3 . 3 9 \%}$ & $\mathbf{- 3 . 4 2 \%}$ \\
\hline
\end{tabular}

Summary Results of August 2005 to August 2006: First, consider the returns for both the optimized and equally weighted portfolios in this time period. Starting with the 10-asset to 18-asset portfolios the returns of the RAMP optimized portfolios outperforms the returns of the Equal Wight in every asset-size portfolio; and with the exception of the 14-asset portfolio, RAMP outperforms the REIT Index in every asset-size as well.

Summary Results of August 2006 to August 2007: This time period represents a definite downturn in the real estate market. During this time period, optimized portfolios are the most efficient portfolios when compared to all other size categories and type. For example, the optimized portfolios in average have a positive $2 \%$ return rate while the equally weighted portfolio and the DJEREIT Index have negative returns.

Summary Results of August 2007 to August 2008: This time period exhibits the greatest negative returns of the three examined time periods. The overall DJEREIT Index reported a $-18.14 \%$ for this time period. Table 2 shows that in this time period the optimized portfolios ranging from 10-asset to 14-asset performed better than both the equal-weight and the market index. Particularly, as Table 1 demonstrates, an optimized 12-REIT portfolio is the most efficient portfolio over all sizes and types.

Summary Results of the Three-Year Period from August 2005 to August 2008: Over the three-year period, from August 2005 to August 2008, results yield some interesting implications regarding overall performance. While in general it is clear that as portfolio size increases, the optimized portfolio significantly outperforms equally weighted 
portfolios and Dow Jones REIT Index. It is unusual, however, to see that some larger size optimized portfolios, 17 and 18 asset portfolios, provide lesser returns compared to the smaller size optimized portfolios. That could reveal another variable. That is, an optimal size portfolio- in this case 12-asset portfolio-- since the difference in performance is even more pronounced at the 12-asset level. As mentioned before, Table-1 demonstrates that for the 3 -year period the return of the RAMP is the highest among all portfolios at $15.2 \%$ while the overall return for the equally weighted portfolio and the DJEREIT Index is $-2.21 \%$ and $-3.42 \%$ respectfully.

\section{SUMMARY}

This paper tests the validity and power of an advanced financial optimization model in one of the hardest hit sectors of our economy - the real estate sector- during the worst economic crisis since the great depression. Under this circumstance, the results of this research demonstrate that diversification through optimization would significantly soften the blow of a serious economic downturn, and an active portfolio manager could avoid the full impact of a crash or severe price declines if he/she considers the recommendations of the RAMP optimization model. Furthermore, to analyze the effects of diversifications through RAMP model we report the short run and the long run returns of ten to eighteen assets portfolios and show the effects of optimization on performance of each and compare the results with equal-weight portfolios and the market index. The returns of portfolios holding less than ten assets are not reported here; actually, the results for the portfolios holding less than 7 assets are inconclusive and no portfolio can consistently or significantly outperform the other portfolios or the market-index. Based on the data presented in Graph-1 and Table 1 and Table 2, it is clear that the portfolios that are generated based on the RAMP optimization model performs better than the equally weighted and DJREIT Index portfolios once the threshold of a 7-asset portfolio is reached. The returns of the ten through eighteen asset portfolios, however, verify that the optimized portfolio consistently outperforms the equally weighted and DJREIT Index portfolios.

\section{CONCLUSION}

The data verifies that RAMP financial optimization model passes the test of financial crisis and provides the most efficient returns for the hardest hit industry during the most severe economic down turn. Based on this data, once a minimum of seven assets are held in the optimized portfolio, returns are superior to that of the equally weighted portfolio and the DJEREIT Index. It is clear from the evidence that an optimized portfolio of EREITs tends to provide superior performance when compared to an equally weighted strategy or even compared to an overall indexed performance measure. In fact the results for the 12-asset optimized portfolio are maximized for the three-year period when 12 assets are held. Therefore, this study presents unambiguous results of supporting the outstanding performance of the RAMP diversification model over a down market and showed that employing riskadjusted modeled allocation process consistently and significantly outperformed the market index.

\section{QUALIFICATIONS}

It is important to note that the outcome of this research is specific to the assets that were included in each portfolio and during the period in which this study was conducted. Due to changing economic conditions in the U.S. and throughout the world, the results may be different for future portfolios. In addition, as equity market becomes more volatile, such results may not hold due to greater imbalances and market inefficiency.

Future studies need to reexamine this question and repeat this work to confirm the consistency of our results over a longer time period. Additionally, we believe that there are many reputable global companies as ADR listing can be included in future research. Thus, future studies need to include these companies in their portfolios.

\section{AUTHOR INFORMATION}

Hamid Ahmadi, Ph.D. Professor of Finance: While being professor of Finance at the Sacramento State University, Professor Ahmadi had an opportunity to be a visiting scholar at the Stanford University. Professor Ahmadi's primary research interest is in asset-allocations, both in the U.S. and abroad. He has written extensively on portfolio management in the United States and also other industrial, but less developed economies. Currently he is studying the relationship between performance of investment portfolios using mathematical modern portfolio theories in 
comparison with less technical approaches to investments and the empirical relationship between optimization and fundamentals. Professor Ahmadi has taught Portfolio Theory, Security Analysis and Portfolio Management, Advanced Investment Strategies, and Financial Institutions and Markets.

James L. Kuhle, Ph.D. Professor of Finance: Professor Kuhle's primary research interests are in common stock selection, mutual fund performance, and real estate asset analysis and valuation. Professor Kuhle has authored over 30 articles related to these topics and his current research interests are in the area of fundamental common stock analysis and selection. Professor Kuhle has taught Investment Analysis, Real Estate Investment Analysis, and Real Estate Valuation.

Sanjay Varshney, Ph.D., CFA, Professor of Finance and Dean: Professor Varshney's research interests include market microstructure, new securities issuance and corporate valuation, and his publications have been cited in numerous academic and practitioner journals. He has also previously worked for Citigroup, Arthur Anderson, and Montgomery Securities. Professor Varshney currently serves on the boards of Wells Fargo Bank, Resource Capital, Sacramento Entrepreneurship Academy, Sacramento Area Regional Technology Alliance (SARTA), The Securities Analysts of Sacramento, and Comstock's Business Magazine.

\section{REFERENCES}

1. Addae-Dapaah, K., S.G. Wee, and M.S. Ebrahim. "Real Estate Portfolio Diversification by Sources of Return.” Journal of Real Estate Portfolio Management, 2002, Volume 8, Issue 1; pp. 1-15.

2. Ahmadi, H. (2009). "2009, the Year of Diversification” Journal of Business \& Economics Research. Volume 7, Number 5.

3. Ahmadi, H., Khoroujik, J (2007). "Do Under-Managed Portfolios Outperform Over-Managed Portfolios?" Journal of Business \& Economics Research. Volume 5, number 4.

4. Ahmadi, H., Khoroujik, J. (2007). "The Empirical Evidence Conclusively Supports Global Investing." International Business \& Economics Research Journal. Volume 6, Number1.

5. Ahmadi, H., Galindo, C. (2005). "Two Staged Portfolio Optimizations". Journal of Business \& Economics Research. Volume 3, number 4.

6. Ahmadi, H. \& Soriano B. C. (2003). "An Analytical Technique for Determining Efficient Portfolios". American Academy of Accounting and Finance. Proceedings.

7. Anderson Randy I, Thomas M Springer. "REIT selection and portfolio construction: Using operating efficiency as an indicator of performance." Journal of Real Estate Portfolio Management. Boston: January-April 2003. Volume 9, Issue 1; pp. 17-28.

8. Booth, P.M. "Real Estate Investment in an Asset/Liability Modeling Context." Journal of Real Estate Portfolio Management, 2002, Volume 8, Issue 1; pp. 183-98.

9. Chen, Hsuan-Chi, Keng-Yu Ho, Chiuling Lu, Cheng-Huan Wu. "Real Estate Investment Trusts: An Asset Allocation Perspective.” Journal of Portfolio Management. Special Real Estate Issue. September 2005. pp. 46-54.

10. Chui, A.C.W., S. Titman, and K.C. Wei. "The Cross Section of Expected REIT Returns.” Real Estate Economics, 2003, Volume 31, Issue 3; pp. 451-479.

11. Jirasakuldech Benjamas, John R Knight. "Efficiency in the Market for REITs: Further Evidence." Journal of Real Estate Portfolio Management. Boston: May-August 2005. Vol.11, Issue 2; p. 123-133.

12. Kuhle James L, Jaime R Alvayay. "The efficiency of equity REIT prices.” Journal of Real Estate Portfolio Management. Boston: October-December 2000. Volume 6, Issue 4; pp. 349-354.

13. Lewis, D., T.M. Springer, and R.I. Anderson. "The Cost Efficiency of Teal Estate Investment Trust; An Analysis with a Bayesian Stochastic Frontier Model.” Journal of Real Estate Finance and Economics, 2003, Volume 26, Issue 1; pp. 65-80.

14. Salter Sean P, "NASDAQ REITs and Optimal Investment Policy: Evidence from 1995 to 2005."

15. Journal of Real Estate Portfolio Management; September-December 2006, Volume 12, Issue 3; pp. 201207.

16. Stevenson Simon. "Ex-ante and ex-post performance of optimal REIT portfolios." Journal of Real Estate Portfolio Management. Boston: Sep-Dec 2002. Volume 8, Issue 3; pp. 199-207.

17. Tse, R.Y.C. "Price-Earnings Ratios, Dividend Yields and Real Estate Stock Prices." Journal of Real Estate Portfolio Management, 2002, Volume 8, Issue 2; pp. 107-113. 